\title{
Performance of wind-powered soil electroremediation process for the removal of 2,4-D from soil
}

\author{
F.L. Souza ${ }^{1}$, J. Llanos*2, C. Sáez ${ }^{2}$, M. R. V. Lanza ${ }^{1}$, M.A. Rodrigo ${ }^{2}$, P. Cañizares ${ }^{2}$ \\ ${ }^{1}$ Institute of Chemistry of São Carlos, University of São Paulo, P.O. Box 780, 13560- \\ 970 São Carlos-SP, Brazil \\ ${ }^{2}$ Chemical Engineering Department, University of Castilla-La Mancha, Edificio \\ Enrique Costa Novella. Campus Universitario s/n, 13005 Ciudad Real, Spain
}

\begin{abstract}
In this work, it is studied a wind-powered electrokinetic soil flushing process for the removal of pesticides from soil. This approach aims to develop an eco-friendly electrochemical soil treatment technique and to face the in-situ treatment of polluted soils at remote locations. Herbicide 2,4 dichlorophenoxyacetic acid (2,4-D) is selected as a model pollutant for the soil treatment tests. The performance of the wind-powered process throughout a 15 days experiment is compared to the same remediation process powered by a conventional DC power supply. The wind-powered test covered many different wind conditions (from calm to near gale), being performed $20.7 \%$ under calm conditions and $17 \%$ under moderate or gentle breeze. According to the results obtained, the wind-powered soil treatment is feasible, obtaining a 53.9\% removal of 2,4-D after 15 days treatment. Nevertheless, the remediation is more efficient if it is fed by a constant electric input (conventional DC power supply), reaching a 90.2\% removal of 2,4-D with a much lower amount of charge supplied (49.2 $\mathrm{A} \mathrm{h} \mathrm{kg}^{-1}$ and $4.33 \mathrm{~A} \mathrm{~h} \mathrm{~kg}^{-1}$ for wind-powered and conventional) within the same operation time.
\end{abstract}


Keywords: Wind turbine, soil remediation, pesticide, renewable energy

*Corresponding author e-mail: javier.llanos@uclm.es 


\section{Introduction}

The use of pesticides is one of the main milestones reached within the last century in the search for overcoming food shortage problems associated to the massive growth of the global population. Unfortunately, the use of pesticides may cause an increase in soil and grown water pollution (Kuhlmeier and Sherwood, 1996). The high toxicity, low biodegradability and, in some cases, carcinogenic nature of pesticides make it necessary to limit their presence in the environment and to develop efficient technologies of soil and water remediation (Cao et al., 2015; Castelo-Grande et al., 2005; Dombek et al., 2004; Malpass et al., 2006). Moreover, the massive use of fossil fuels as a primary source of energy is leading to an unsustainable rate of anthropogenic greenhouse gases emissions, being a major cause for climate change. Thus, renewable energy sources play a key role in providing energy sources services in a sustainable, secure and affordable manner.

One of the most interesting technologies to remove pollutants from soil is electrokinetic soil flushing (EKSF) (Alshawabkeh et al., 1999; Rodrigo et al., 2014; Yeung and Gu, 2011). This process is based in the application of an electric field directly to the soil to be treated in order to promote the mobilized ionic species and also to generate an electro-osmotic flow towards the cathode that helps to remove the soluble pollutants (Yeung, 2006).

One of the main opportunities in the intensification of soil and wastewater electrochemical treatment processes is the possibility of coupling these technologies to renewable sources of energy, such as photovoltaic or wind devices (Carta et al., 2003; Souza et al., 2015a; Souza et al., 2015b). Apart from allowing the design of eco-friendly environmental remediation processes, this coupling is especially interesting if the treatment of polluted soils is to be applied in remote locations, where the access to the 
main electricity grid is difficult or not possible (Bundschuh et al., 2010). Unfortunately, these renewable sources of energy are characterized by an uneven production profile, and little attention have been paid to the effect of this type of electric input in the electrochemical remediation of polluted soils, which is usually studied with an almost constant power input (Ma et al., 2010; Pham et al., 2009).

Some recent works have dealt with the coupling of renewable sources of energy to EKSF devices. These works have been focused on the use of solar photovoltaic panels and the treatment of soils polluted with metals (Hassan et al., 2015; Jeon et al., 2015; Yuan et al., 2009; Zhang et al., 2015) or fluorine (Zhou et al., 2013). From the best of the author's knowledge, no previous works of wind-powered electrokinetic soil flushing have been published.

In the present work, a wind-powered soil electroremediation (WPSER) process is presented for the treatment of soil polluted with the herbicide 2,4 dichlorophenoxyacetic acid (2,4-D). In the proposed system, a cell for the electrokinetic soil flushing device is directly connected to a wind turbine, without the use of intermediate batteries. With this system, a short-term soil flushing test (15 days duration) was carried out. Results are compared to the behavior of the same cell connected to a conventional DC power supply. The main aim of the work is to check the technical feasibility of the direct connection of wind turbine to a soil electroremediation system and to evaluate the influence that the random feed of the energy (characteristic of wind-based generation systems) has on the performance of the process. Although this work is focused on the removal of 2,4-D, it is aimed to be the base for future works regarding the removal of other kind of pollutants (organic and inorganic) by WPSER technique. 


\section{Material and methods}

\subsection{Chemicals}

Kaolinite, provided by Manuel Riesgo Chemical Products (Madrid, Spain), was used as a model of clay soil. Properties of this synthetic clay soil were provided by the commercial supplier, and are detailed in Table 1. All chemicals, including anhydrous sodium sulphate, sodium phosphate (Fluka, Spain), 2,4-dichlorophenoxyacetic acid (Sigma-Aldrich) were analytical grade and used as received. Acetonitrile HPLC grade (Sigma-Aldrich, Spain) was used for the mobile phase. Double deionized water (Millipore Milli-Q system, resistivity $=18.2 \mathrm{M} \Omega \mathrm{cm}$ at $25^{\circ} \mathrm{C}$ ) was used to prepare all solutions.

\subsection{Electrokinect cell}

Bench-scale setup was made of methacrylate and consists of an orthoedric tank divided into five compartments. It is described in detail elsewhere (Mena Ramírez et al., 2014). For the wind-powered test, a Bornay 600 wind power turbine provided by Bornay Aerogeneradores (Alicante, Spain) was used to generate electricity. Specifications were provided elsewhere (Souza et al., 2015a). The duration of the experiment was two weeks.

To prepare the soil column, firstly, a pesticide solution containing $500 \mathrm{mg} \mathrm{dm}^{-3}$ of 2,4-D was prepared with tap water. This solution was used to pollute the soil, up to a $30 \%$ of the moisture. Then, herbicide-polluted soil was compacted manually in the central compartment of the cell. This compaction was done very carefully, in order to avoid the formation of heterogeneities in the soil that may result in preferential paths for the hydraulic fluid transport. Tap water was used as electrolyte in the soil and in the electrodic wells. The loses of water due to the evaporation process and also due to the 
electro-osmosis were replaced with the same electrolyte, added to the anodic well by means of an on/off regulation loop.

\subsection{Analysis procedures}

Daily, the electrical current, the temperature of different portions of the soil, the electroosmotic volume removed from the cathode collector, $\mathrm{pH}$, pesticide and TOC concentration of the electro-osmotic fluid were monitored. The liquids contained in the electrolyte wells were also daily monitored measuring $\mathrm{pH}$, conductivity and pesticide concentration. At the end of the experiment, a post mortem analysis was carried out to evaluate the final state of the treated soil (post-study characterization) and $\mathrm{pH}$, humidity and pesticide concentration were measured. For this analysis, the soil compartment was divided into sixteen equal sections (four from anode to cathode and 4 from top to botton), being section 1 that closest to the anode. Sampling procedure of each point of the soil consists of taking it out carefully from the set up and manually homogenizing it. Once it was homogeneous, representative samples were taken for carrying out each analysis. Measurement procedures for the moisture, $\mathrm{pH}, 2,4-\mathrm{D}$ can be found elsewhere (Risco et al., 2016).

\section{Results and discussion}

Powering soil electroremediation with green energy is a challenge in the search for novel eco-friendly environmental remediation processes. Duration of electroremediation treatment tests is typically very long and due to the large time-constants of the processes involved, coupling of a non-continuous supply should not have a negative impact on results. This work aims at studying the differences between the removal of a model 
pesticide (2,4-D) using EKSF powered directly with DC power supply or with the output of a wind turbine during a 15 days long treatment. Due to the anode material selected (graphite) the oxidation of 2,4-D on the cathode can be considered negligible. Moreover, it has been tested (data not shown) that the adsorption of 2,4-D in the synthetic soil selected is almost nil. Finally, it has been described in literature that biological degradation of similar refractory organic compounds is not possible due to the type of soil (Mena et al., 2014) and that the volatility of this molecule is also negligible when it is in anionic form (the case under the working $\mathrm{pH}$ of the present work). For these reasons, it can be stated that the main mechanism for 2,4-D removal is its electrokinetic flushing from the soil, being the discussion focused on this removal mechanism.

\subsection{Wind turbine behaviour}

Fig. 1 shows the evolution of wind speed throughout the soil remediation test and the classification of this variable according to the International Beaufort wind force scale. As it can be observed, wind speed behaves as a noisy signal, characteristic of windbased energy supplies (de la Nuez Pestana et al., 2004; Souza et al., 2015a), with an average value of $1.93 \mathrm{~m} \mathrm{~s}^{-1}$ and a maximum speed of $16.1 \mathrm{~m} \mathrm{~s}^{-1}$ (at the beginning of the eleventh day). Within the first part of the test (first seven days), wind speed was very low (average of $1.07 \mathrm{~m} \mathrm{~s}^{-1}$ ), and it increased within the second part of the experiment (from days 8 to 15 ), reaching an average value of $2.97 \mathrm{~m} \mathrm{~s}^{-1}$. Then, $20.7 \%$ of the test was carried out at calm condition, meanwhile approximately $17 \%$ was performed under moderate or gentle breeze, the most appropriate condition for electricity production in an inland area. According to this data, this test covers from calm to near gale wind 
speed and it can be considered as a good proof of concept of this technology working under real wind conditions.

\section{Figure 1}

The result of this noisy input is a variable energy production of the wind turbine. This result is observed in Fig. 2, which represents the daily average intensity and the electric charge passed through the system per day of experiment. According to the manufacturer, the threshold of wind speed required to turn on the electricity generation system is $3.5 \mathrm{~m} \mathrm{~s}^{-1}$. This information is confirmed by the data gathered in Fig. 2, where it is observed that the intensity produced by the wind turbine was almost nil during the first seven days of the test. On the contrary, the increase in wind speed from the eighth day produced a marked growth in the intensity fed to the EKSF cell. The average intensity registered was $0.45 \mathrm{~A}$ (with a maximum value of $9.6 \mathrm{~A}$ ) and the total charge passed through the system was equal to $49.2 \mathrm{~A} \mathrm{~h} \mathrm{~kg}^{-1}$ of soil.

\section{Figure 2}

\subsection{Performance of EKSF device: comparison of energy source.}

Figure 3 shows the changes in the average current density applied, temperature and flow rates (electro-osmosis and evaporation fluxes) during the two tests carried out to evaluate the effect of powering an electrokinetic soil flushing remediation with wind turbines. In one of the experiments, the electrodes are directly powered with the wind turbines (no intermediate batteries) while in the other test the system is powered with a conventional power supply, for which the target has been to keep an electric field of 1 $\operatorname{VDC~} \mathrm{cm}^{-1}$.

\section{Figure 3}


As it can be observed, the resulting electric current produced when the system is fed with a power supply decreases continuously during the experiment from an initial value of $4.5 \mathrm{~A} \mathrm{~m}^{-2}$ down to $3.0 \mathrm{~A} \mathrm{~m}^{-2}$. Taking into account that electric field was kept constant in this test, this decrease in the electric current produced has to be explained in terms of an increase in the ohmic resistance of the soil in the electrolyte contained in the wells. However, this increase in the resistance is not reflected on the temperature changes as it can be observed in the figure in which a soft decrease in the temperature during the test is observed. Regarding the flowrates of water produced in the soil column, electroosmotic flowrate decreases during the test from an initial value of 1.4 down to $0.7 \mathrm{~cm} \mathrm{~d}^{-}$ 1. It is a very low velocity but within the expected range. Regarding the evaporation flowrate, it fluctuates around $0.05 \mathrm{~cm} \mathrm{~d}^{-1}$, being much less important than the electrokinetic flux.

In comparing both systems (powered with power supply or with wind turbine), it is important to point out that average current density changes very significantly depending on the day, being almost nil for several days and huge (as compared to the systems powered with power supply) for the second part of the test. According to the observed results, this uneven feeding of the wind-powered system does not favour the generation of a constant electro-osmotic flow. Consequently, the average electro-osmotic flow is higher for the conventionally fed system although the intensity supplied to the cell is lower in this case.

Next, Fig. 4 shows the moisture distribution in the soil measured after the test (postmortem analysis) for both energy supplies. To explain the moisture at the end of the electroremediation tests, water fluxes have to be taken into account. As shown in the Figure, moisture of the soil after the treatment is higher in the case of the system powered with the wind turbine than in the case of the soil electroremediation powered 
with a power supply, despite the greater fluxes observed in the conventionally powered system. It clearly indicates that non-continuous supply of electricity does not favour the formation of fluxes and hence it favours the extra accumulation of water in the soil.

\section{Figure 4}

Fig. 5.a represents the evolution of $\mathrm{pH}$ in catholyte and anolyte throughout the tests fed with power supply and with wind turbines. As observed, $\mathrm{pH}$ changes are as expected in the electroremediation powered with the AC-DC power converter: it is obtained a very rapid acidification in the anolyte and simultaneously a basification in the catholyte. On the contrary, the almost nil amount of energy received by the soil powered by the air turbine during the first days (calm conditions) made that the profiles of $\mathrm{pH}$ in the anolyte and catholyte change in a very different fashion and that only after the first windy day the $\mathrm{pHs}$ become extreme in the electrolytes. At this point, it is worth mentioning that $\mathrm{pH}$ was measured at the end of each day and may not represent the punctual variation of the system behaviour but the average of the cell performance within the day considered.

\section{Figure 5}

This behaviour is related to the final $\mathrm{pH}$ and conductivity found in different portions of the soil after the electroremediation tests (Fig. 5.b). Final $\mathrm{pH}$ in the soil treated by conventional power supply was much more altered than that if the system is powered by wind turbine, which corresponds to the extreme $\mathrm{pH}$ observed in the electrolytes from the first days of the test.

Finally, Fig. 6 represents the final concentration of 2,4-D in the treated soil. As observed, removal of 2,4-D is significantly lower in the case of the remediation test powered by the wind turbine. This result is in agreement with the lower electro-osmotic 
flow measured in the case of the wind-powered system. In both tests, the concentration in the soil was higher in the soil sections that were placed closer to the anode. This result may be explained in terms of the electromigration of 2,4-D, which behaves as an anion at the range of $\mathrm{pH}$ values measured throughout the test (Jackman et al., 2001).

\section{Figure 6}

After the 15 days long tests, the removal of 2,4-D reaches $90.2 \%$ and $53.9 \%$ in the electroremediation powered with DC power supply and wind turbine, respectively. The total applied charge passed is 49.2 and $4.33 \mathrm{~A} \mathrm{~h} \mathrm{~kg}^{-1}$ of soil in both system. This means that the unforeseeable supply of the wind turbine results in a much less efficient system, in which a much higher amount of charge is required to reach the same removal of pollutants in the soil. These results opposite previous results obtained for the coupling of wind turbines with electrolytic cells to deplete pesticides from liquid wastes (Souza et al., 2015a). In this case, no significant differences were observed between the electrolysis powered with wind turbines and with conventional power supply. This can be explained in terms of the more complex processes that occur in EKSF processes and the great interaction among them. The majority of soil electroremediation studies published so far works with a constant voltage and an almost constant power applied to the system. With these conditions, it is possible to reach a pseudo-steady state in which pollutants are slowly removed by a combination of electro-osmosis, ion migration and electrophoresis (Pazos et al., 2010). Changing continuously energy fed to the process lead to huge inefficiencies and to the continuous interruption and re-start up of the most significant processes. Influence of this discontinuous supply on electro-osmotic flows seems to be very important, making the flushing of the soil unpractical. 


\section{Conclusions}

Electrokinetic soil flushing can be successfully powered with wind turbines. The continuous variation of the electrical input of wind turbine makes the wind-powered soil electroremediation less efficient than the system fed by conventional power supply. After the 15 days long tests, it was possible to remove $90.2 \%$ and $53.9 \%$ of $2,4-\mathrm{D}$ in the electroremediation powered with DC power supply and air turbine, respectively. During the period of the wind-powered test, $20.7 \%$ of the time calm conditions were observed, meanwhile approximately $17 \%$ was performed under moderate or gentle breeze, the most appropriate conditions for electricity production. Calm conditions are not useful for providing energy to the soil remediation system, if spite wind speed is not negligible.

\section{Acknowledgements}

The authors acknowledge funding support from the EU and Spanish Government through the MINECO Project CTM2013-45612-R, FEDER 2007-2013 PP201010 (Planta Piloto de Estación de Estación de Regeneración de Aguas Depuradas) and INNOCAMPUS. Brazil government by grant 2014/02580-7, São Paulo Research Foundation (FAPESP) is gratefully acknowledged. 


\section{References}

Alshawabkeh, A.N., Yeung, A.T., Bricka, M.R., 1999. Practical aspects of in-situ electrokinetic extraction. Journal of Environmental Engineering 125, 27-35.

Bundschuh, J., Litter, M., Ciminelli, V.S.T., Morgada, M.E., Cornejo, L., Hoyos, S.G., Hoinkis, J., Alarcón-Herrera, M.T., Armienta, M.A., Bhattacharya, P., 2010. Emerging mitigation needs and sustainable options for solving the arsenic problems of rural and isolated urban areas in Latin America - A critical analysis. Water Research 44, 58285845.

Cao, X., Song, H.L., Yu, C.Y., Li, X.N., 2015. Simultaneous degradation of toxic refractory organic pesticide and bioelectricity generation using a soil microbial fuel cell. Bioresource Technology 189, 87-93.

Carta, J.A., González, J., Subiela, V., 2003. Operational analysis of an innovative wind powered reverse osmosis system installed in the Canary Islands. Solar Energy 75, 153168.

Castelo-Grande, T., Augusto, P.A., Barbosa, D., 2005. Removal of pesticides from soil by supercritical extraction - A preliminary study. Chemical Engineering Journal 111, 167-171.

de la Nuez Pestana, I., Latorre, F.J.G., Espinoza, C.A., Gotor, A.G., 2004. Optimization of RO desalination systems powered by renewable energies. Part I: Wind energy.

Desalination 160, 293-299.

Dombek, T., Davis, D., Stine, J., Klarup, D., 2004. Degradation of terbutylazine (2chloro-4-ethylamino-6-terbutylamino-1,3,5- triazine), deisopropyl atrazine (2-amino-4chloro-6-ethylamino-1,3,5-triazine), and chlorinated dimethoxy triazine (2-chloro-4,6dimethoxy-1,3,5-triazine) by zero valent iron and electrochemical reduction.

Environmental Pollution 129, 267-275.

Hassan, I., Mohamedelhassan, E., Yanful, E.K., 2015. Solar powered electrokinetic remediation of $\mathrm{Cu}$ polluted soil using a novel anode configuration. Electrochimica Acta. Jackman, S.A., Maini, G., Sharman, A.K., Sunderland, G., Knowles, C.J., 2001. Electrokinetic movement and biodegradation of 2,4-dichlorophenoxyacetic acid in silt soil. Biotechnology and Bioengineering 74, 40-48.

Jeon, E.K., Ryu, S.R., Baek, K., 2015. Application of solar-cells in the electrokinetic remediation of As-contaminated soil. Electrochimica Acta.

Kuhlmeier, P.D., Sherwood, S.P., 1996. Treatability of inorganic arsenic and organoarsenicals in groundwater. Water Environment Research 68, 946-951.

Ma, J.W., Wang, F.Y., Huang, Z.H., Wang, H., 2010. Simultaneous removal of 2,4dichlorophenol and $\mathrm{Cd}$ from soils by electrokinetic remediation combined with activated bamboo charcoal. Journal of Hazardous Materials 176, 715-720.

Malpass, G.R.P., Miwa, D.W., Machado, S.A.S., Olivi, P., Motheo, A.J., 2006.

Oxidation of the pesticide atrazine at DSA® electrodes. Journal of Hazardous Materials 137, 565-572.

Mena, E., Villaseñor, J., Cañizares, P., Rodrigo, M.A., 2014. Effect of a direct electric current on the activity of a hydrocarbon-degrading microorganism culture used as the flushing liquid in soil remediation processes. Separation and Purification Technology 124, 217-223.

Mena Ramírez, E., Villaseñor Camacho, J., Rodrigo Rodrigo, M.A., Cañizares Cañizares, P., 2014. Feasibility of electrokinetic oxygen supply for soil bioremediation purposes. Chemosphere 117, 382-387. 
Pazos, M., Rosales, E., Alcántara, T., Gómez, J., Sanromán, M.A., 2010.

Decontamination of soils containing PAHs by electroremediation: A review. Journal of Hazardous Materials 177, 1-11.

Pham, T.D., Shrestha, R.A., Virkutyte, J., Sillanpää, M., 2009. Combined ultrasonication and electrokinetic remediation for persistent organic removal from contaminated kaolin. Electrochimica Acta 54, 1403-1407.

Risco, C., López-Vizcaíno, R., Sáez, C., Yustres, A., Cañizares, P., Navarro, V., Rodrigo, M.A., 2016. Remediation of soils polluted with 2,4-D by electrokinetic soil flushing with facing rows of electrodes: A case study in a pilot plant. Chemical Engineering Journal 285, 128-136.

Rodrigo, M.A., Oturan, N., Oturan, M.A., 2014. Electrochemically Assisted Remediation of Pesticides in Soils and Water: A Review. Chemical Reviews 114, 87208745.

Souza, F.L., Lanza, M.R.V., Llanos, J., Sáez, C., Rodrigo, M.A., Cañizares, P., $2015 a$. A wind-powered BDD electrochemical oxidation process for the removal of herbicides. Journal of Environmental Management 158, 36-39.

Souza, F.L., Saéz, C., Llanos, J., Lanza, M.R.V., Cañizares, P., Rodrigo, M.A., $2015 b$. Solar-powered CDEO for the treatment of wastewater polluted with the herbicide 2,4-D. Chemical Engineering Journal 277, 64-69.

Yeung, A.T., 2006. Contaminant extractability by electrokinetics. Environmental Engineering Science 23, 202-224.

Yeung, A.T., Gu, Y.Y., 2011. A review on techniques to enhance electrochemical remediation of contaminated soils. Journal of Hazardous Materials 195, 11-29.

Yuan, S., Zheng, Z., Chen, J., Lu, X., 2009. Use of solar cell in electrokinetic remediation of cadmium-contaminated soil. Journal of Hazardous Materials 162, 15831587.

Zhang, S., Zhang, J., Cheng, X., Mei, Y., Hu, C., Wang, M., Li, J., 2015. Electrokinetic remediation of soil containing $\mathrm{Cr}(\mathrm{VI})$ by photovoltaic solar panels and a DC-DC converter. Journal of Chemical Technology and Biotechnology 90, 693-700.

Zhou, M., Zhu, S., Liu, Y., Wang, X., 2013. Removal of fluorine from contaminated soil by electrokinetic treatment driven by solar energy. Environmental Science and Pollution Research 20, 5806-5812. 
Table caption

Table 1. Main properties of the soil treated.

Table 1

\begin{tabular}{|c|c|c|c|c|c|}
\hline \multicolumn{2}{|c|}{ Mineralogy } & \multicolumn{2}{|c|}{$\begin{array}{l}\text { Particle size } \\
\text { distribution }\end{array}$} & \multicolumn{2}{|c|}{ Properties } \\
\hline $\mathrm{Al}_{2} \mathrm{O}_{3}$ & $34.50 \%$ & Clay & $78 \%$ & $\begin{array}{c}\text { Hydraulic } \\
\text { conductivity }\end{array}$ & $\begin{array}{c}10^{-7} \mathrm{~cm} \\
\mathrm{~S}^{-1}\end{array}$ \\
\hline $\mathrm{CaO}$ & $0.10 \%$ & Sand & $4 \%$ & Organic content & 0\% \\
\hline $\mathrm{Fe}_{2} \mathrm{O}_{3}$ & $0.58 \%$ & Silt & $18 \%$ & Bulk density & $\begin{array}{l}2.6 \mathrm{~g} \\
\mathrm{~cm}^{-3}\end{array}$ \\
\hline $\mathbf{K}_{2} \mathbf{O}$ & $0.75 \%$ & Grave & $\mathbf{0 \%}$ & pH & 4.9 \\
\hline \multicolumn{6}{|c|}{$\mathrm{SiO}_{2} \quad 52.35 \%$} \\
\hline \multicolumn{6}{|c|}{$\mathrm{TiO}_{2} \quad \mathbf{0 . 2 7 \%}$} \\
\hline PPC & $11.42 \%$ & & & & \\
\hline
\end{tabular}




\section{Figure captions}

Figure 1. Changes in the wind speed during the period of operation of the wind turbine. Onset: Distribution of wind velocities monitored classified according to the International Beaufort wind force scale.

Figure 2. Daily average value of intensity $(\Delta)$ and amount of charge passed ( $\mathbf{})$ for 15 days experiment of wind-powered soil remediation device.

Figure 3. Changes during the electroremediation tests powered by air turbine (full symbols) and DC power supply (empty symbols) a) applied current density $(\boldsymbol{\Lambda}, \triangle$ ) and temperature of the soil column measured in a central position $(\boldsymbol{\square}, \square)$ b) evaporation fluxes $(\boldsymbol{\square}, \square)$ and electro-osmotic fluxes $(\boldsymbol{\Lambda}, \triangle)$

Figure 4. Moisture distribution in the soil after the 15 days remediation tests powered with air turbine (full points) and power supply (empty points). Upper right position $(\bullet$, $\circ)$, upper left position $(\boldsymbol{\square}, \square)$, bottom right position $(\diamond, \diamond)$ and bottom left position $(\boldsymbol{\Lambda}$, $\Delta)$.

Figure 5. Changes in $\mathrm{pH}$ during the electroremediation tests powered by air turbine (full symbols) and DC power supply (empty symbols) a) $\mathrm{pH}$ in the catholyte and anolyte $(\boldsymbol{\Lambda}, \triangle)$ b) Upper right position $(\bullet, \circ)$, upper left position $(\boldsymbol{\bullet}, \square)$, bottom right position $(\diamond, \diamond)$ and bottom left position $(\boldsymbol{\Delta}, \Delta)$.

Figure 6. 2,4-D pesticide map of the soil after the remediation tests powered by air turbine (full points) and power supply (empty points). Upper right position $(\bullet, \circ)$, upper left position $(\boldsymbol{\square}, \square)$, bottom right position $(\diamond, \diamond)$ and bottom left position $(\boldsymbol{\Delta}, \Delta)$. 


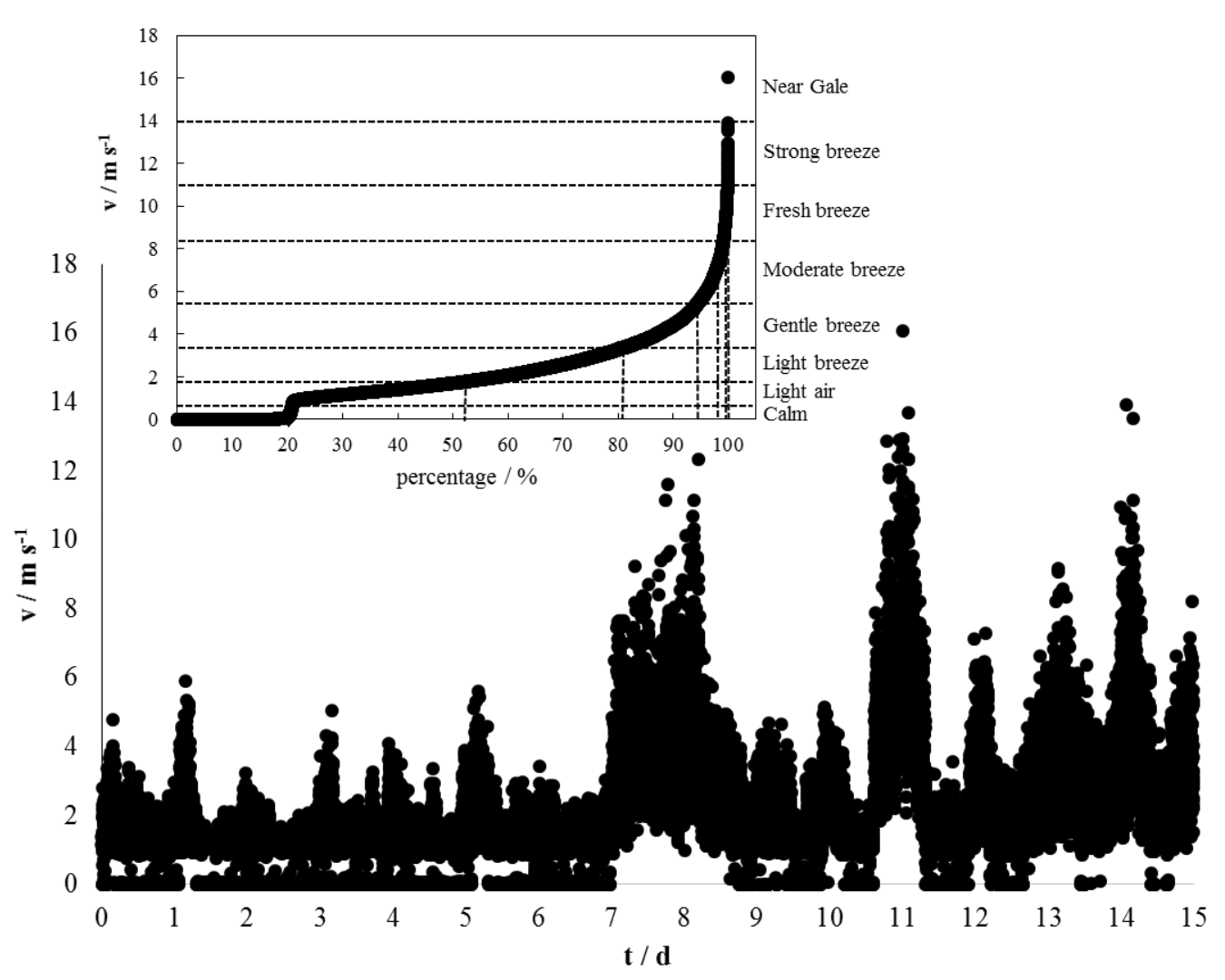

Figure 1 


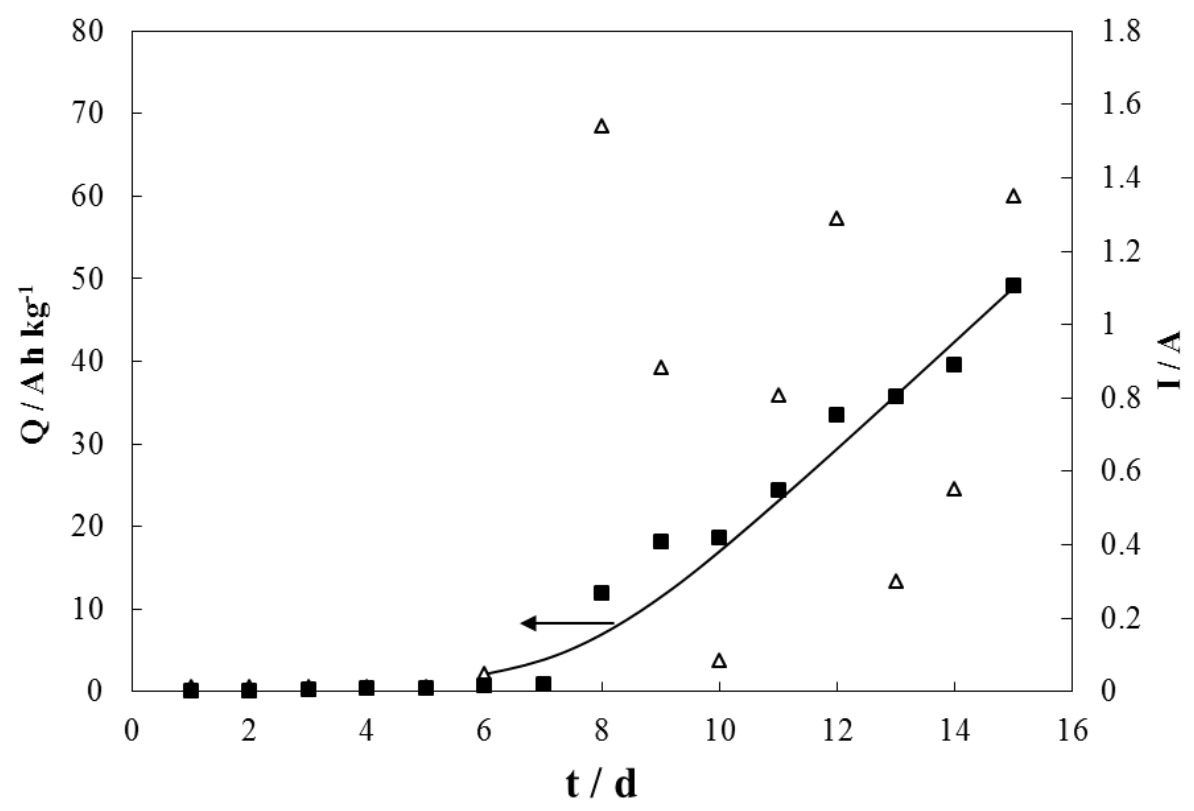

Figure 2
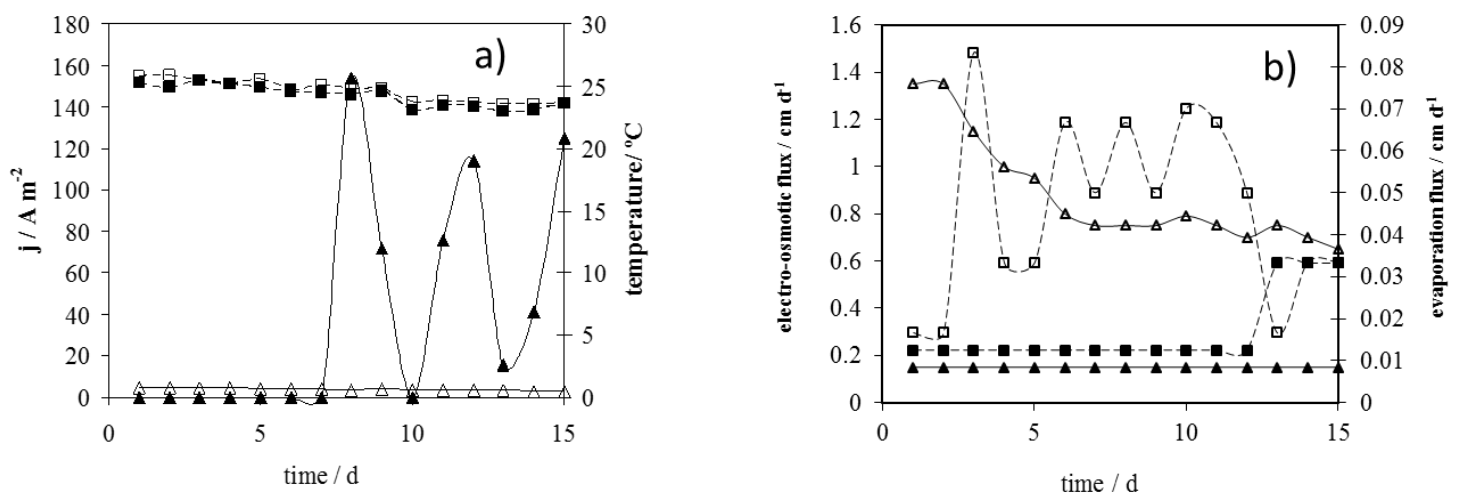

Figure 3 


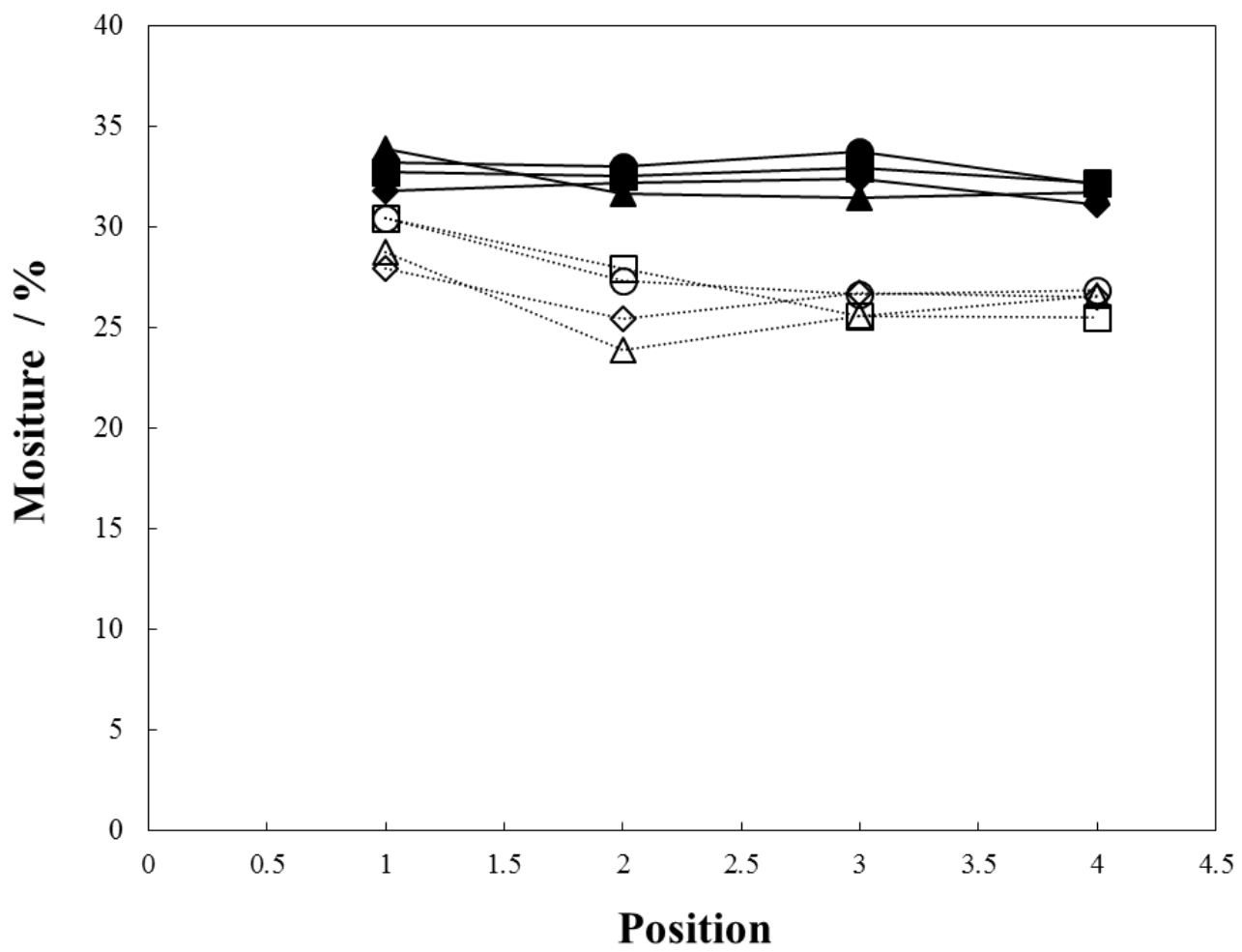

Figure 4
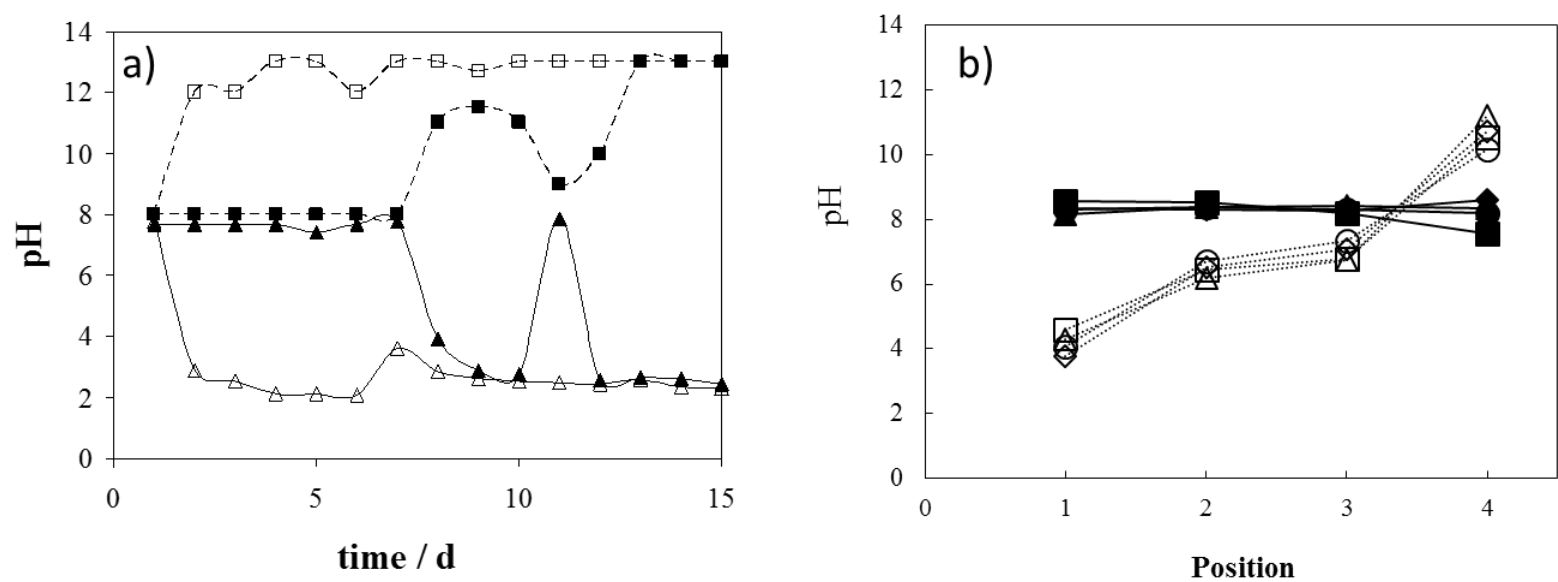

Figure 5 


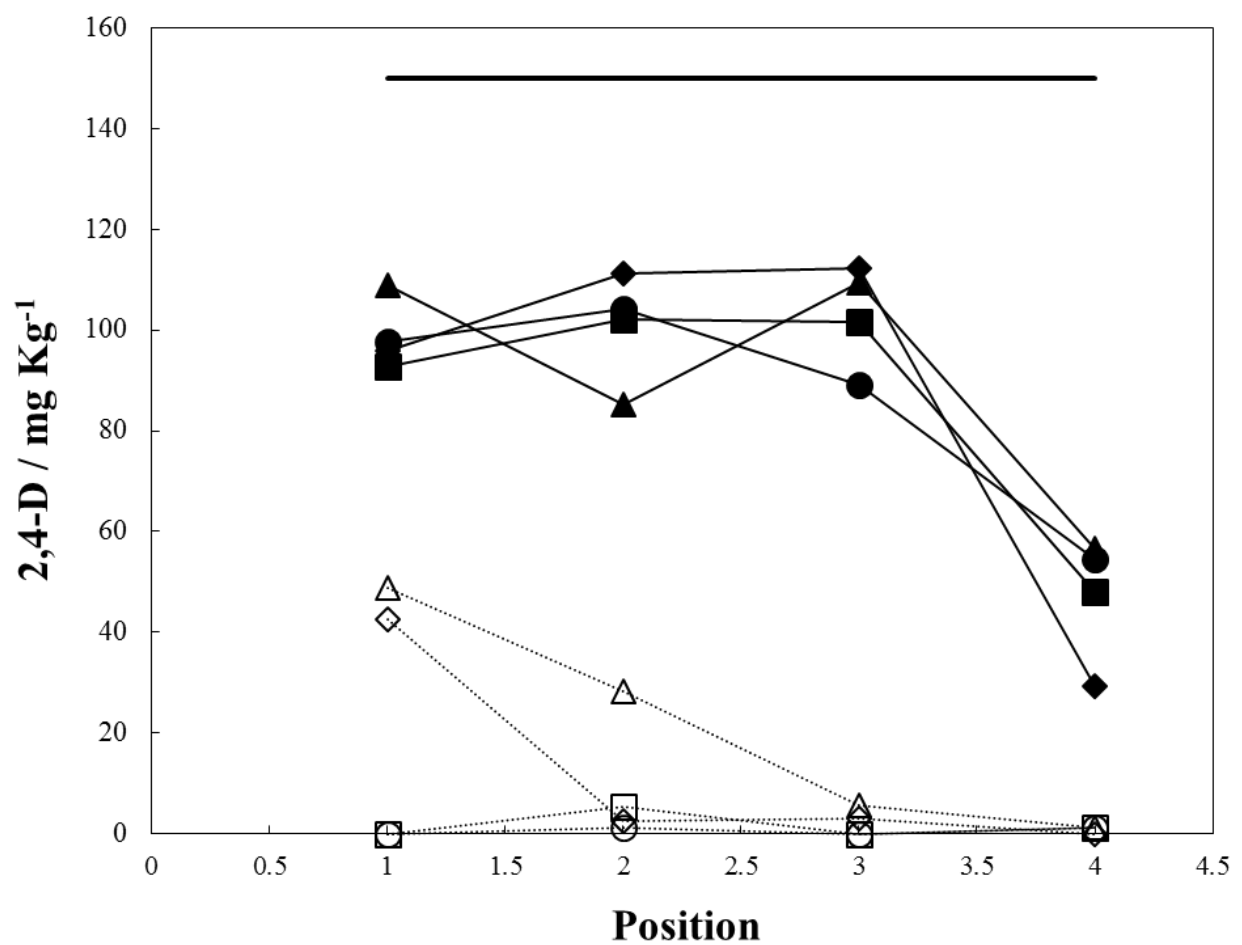

Figure 6 